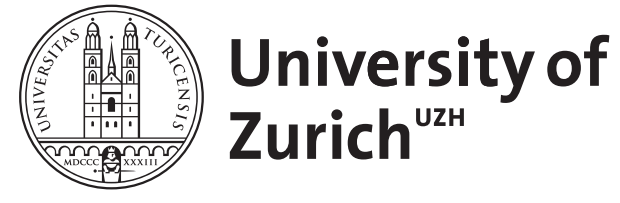

Zurich Open Repository and Archive

University of Zurich

University Library

Strickhofstrasse 39

CH-8057 Zurich

www.zora.uzh.ch

Year: 1997

\title{
Introduction to the fourth ECAP Newsletter
}

Steinhausen, Hans-Christoph

DOI: https://doi.org/10.1007/bf00539932

Posted at the Zurich Open Repository and Archive, University of Zurich

ZORA URL: https://doi.org/10.5167/uzh-156568

Journal Article

Published Version

Originally published at:

Steinhausen, Hans-Christoph (1997). Introduction to the fourth ECAP Newsletter. European Child Adolescent Psychiatry, 6(4):240.

DOI: https://doi.org/10.1007/bf00539932 
The present newsletter continues with a series of reports on the status of child and adolescent psychiatry in various European countries. Irma Moilanen, current president of the Finnish Child Psychiatry Association, describes the differences in the training schemes as compared to other European regions and the plans to develop programs for special competencies. Despite a relatively short history of educational curricula, Finland has obviously succeeded to train an impressive number of child and adolescent psychiatrists who serve the growing needs for assessment and treatment in the population. Her report also gives a vivid impression of the societal changes in the recent past with all the implica-

Prof. Dr. Dr. H.-C. Steinhausen ( )

Department of Child and Adolescent Psychiatry

University of Zurich

Freiestrasse 15

CH-8028 Zurich, Switzerland tions for child and adolescent psychiatric services and practices. From all these activities, including an impressive amount of research activities, one gets the impression that the various contributions of child and adolescent psychiatry in Finland have led to a situation that is characterized by respect and appreciation for our discipline both among professionals and the public.

The newsletter contains a related document dealing with the European Forum for all Psychiatric Trainees (EFPT). We are told that the Forum is aiming at the promotion and improvement of training curricula and contributions to the development of European training standards. The invitations of the Forum certainly deserve the support of our community of specialists. The reader is specifically refereed to the information on the first congress of the EFPT as given in the document.

Finally, all ECAP readers are again kindly requested to send news from their respective countries that they would like to be incorporated into the ECAP newsletter. 